Article

\title{
Landscape Connectivity as a Tool in Green Space Evaluation and Optimization of the Haidan District, Beijing
}

\author{
Shiyi Guo ${ }^{1,2}$, Kaoru Saito ${ }^{2}$, Weida Yin ${ }^{1, *}$ and Chang $\mathrm{Su}^{3}$ \\ 1 School of Landscape Architecture, Beijing Forestry University, Beijing 100083, China; \\ 6315612792@edu.k.u-tokyo.ac.jp \\ 2 Graduate School of Frontier Science, The University of Tokyo, Kashiwa 277-8563, Japan; \\ kaoru@nenv.k.u-tokyo.ac.jp \\ 3 Graduate School of Horticulture, Chiba University, Matsudo 271-8510, Japan; agda1060@chiba-u.jp \\ * Correspondence: maximus@bjfu.edu.cn
}

Received: 26 April 2018; Accepted: 9 June 2018; Published: 13 June 2018

\begin{abstract}
The demand for urban construction has placed growing pressure on biodiversity conservation. In China, landscape fragmentation caused by rapid urbanization has resulted in an immense amount of damage to the ecological system. Taking the Haidian District of Beijing as the study area, this study distinguishes the vital patches and corridors for landscape connectivity maintenance through morphological spatial pattern analysis (MSPA), the probability of connectivity (PC), and the least-cost path analysis. Although we adopted and combined these methods from the existing research about landscape modeling, we went deeper into two parameters: the resistance value and the distance threshold. In order to get a species-specific result, we selected two focal species: the ring-necked pheasant (Phasianus colchius) and the raccoon dog (Nyctereutes procyonoides), whose biological characteristics and habitat types are assumed to represent most of the habitats in Beijing. The result shows the different habitats and corridors for two species. Then, the results of two simulated scenarios are overlaid to obtain the final landscape pattern. Based on this case study, we propose a paradigm of ecological network identification of multiple species, which may contribute to landscape modeling and green space planning.
\end{abstract}

Keywords: green space; landscape connectivity; focal species; least-cost path; morphological spatial pattern analysis

\section{Introduction}

\subsection{Social Background}

Green space broadly refers to a natural or seminatural open space with considerable vegetation coverage [1], including woodland (forest), grassland, farmland, etc. [2]. In the urban context, green space is inevitably turned over to the built-up area for development, especially in rapidly developing cities. Due to the public ownership of land (a land law) in China, the land belongs to the central and local governments, and land users only have usage rights to the land, instead of the land itself or any resources in or below the land. Master plan and green space planning dominated by the local government are regarded as a guide of green space management. In this context, planning is the most direct way to control urban expansion and mitigate landscape fragmentation.

However, there is a lack of theoretical research in current green space planning, especially for its ecological function. Current green space planning includes the location, shape, and function of each green space. The area, number, and accessibility are paid more attention, rather than green space 
planning's role in biodiversity conservation. Although it is important for urban green space to satisfy the human demand of recreation, the potential ecological function of it can be explored with more methodological consideration of ecology or biology. In the context of the inevitable biodiversity with urbanization, what can be done to mitigate the damage to the natural environment through a more efficient green space planning?

\subsection{Academic Background}

Due to the rich biological resources in urban development areas, the contradiction between green space conservation and urban construction has become one of the most important problems in densely populated areas [3]. Landscape fragmentation, one of the consequences of urban expansion, is defined as habitat loss through the spread of artificial surfaces and the split of remaining habitat areas [4]. Landscape fragmentation will limit the movement of organisms between habitats, which can be a huge threat to biodiversity; especially in small isolated patches, the gene exchange will be greatly reduced [5-7].

Landscape connectivity, the opposite of landscape fragmentation, describes the facilitating or impeding effect of the landscape on the dispersal of species among habitats [8,9]. It is used to evaluate the ecological service function of a certain landscape by quantifying landscape patterns from a macro point of view. In recent decades, an interdisciplinary field called landscape ecology has proposed new methods to understand how landscape patterns influence ecological processes $[10,11]$, for instance, biodiversity [12,13] and the warmer microclimate-heat island effect [14-16]. In recent years, increasing numbers of ecologists, biologists, other scientists, planners, and engineers have taken part in the interdisciplinary research about the ecological processes of urban ecosystems [17]. Landscape connectivity has become the focus of current landscape ecology research [18].

Landscape metrics and models focused on simulating ecological processes have become trends in landscape ecology [19-21]. In terms of the dispersal probability among habitats, the connectivity between habitats can be characterized by a probability model, for example, the interpatch Euclidean distance [22,23]. Numerous landscape metrics and models were therefore developed to quantify landscape configuration and to further evaluate ecosystem services or forest management. Meanwhile, the number of cases of landscape planning or green space planning using landscape connectivity metrics or models has increased [24-27].

According to the existing research about species' response to landscape connectivity, it is generally accepted that landscape connectivity plays an important role in biodiversity, although it is case by case among all species. However, the arguments between biology and biogeography still exist [28]. There is a growing skepticism that it is unreliable to identify ecological corridors without including details such as animal behavior and intraspecific differences $[29,30]$. For example, for species characterized by low dispersal distance, they will be more sensitive to landscape connectivity; the barrier effect of a certain land cover is also species specific [31]. In this study, seeking to make a more comprehensive assessment of landscape connectivity, the core habitats and corridors will be identified according to the habitat type and dispersal distance of the focal species. We will address the following methodological problems:

(a) How can we optimize the recognition of habitats and corridors in existing research from a species-specific perspective? In this study, landscape is no longer a homogeneous area. Instead, it is defined by each species according to its habitat; besides, the distance threshold between two green spaces depends on the dispersal distance of a certain species.

(b) How can we get a multispecies result? We provide a paradigm for ecological network identification of multiple species, such as birds, mammals, plants, a community, or all species. For instance, we select two focal species as an example, which is expected to represent all species in the study area. The final ecological network can be obtained by overlaying the scenarios of each species involved. 


\section{Study Area and Data}

\subsection{Study Area}

Beijing $\left(39^{\circ} 38^{\prime}-41^{\circ} 05^{\prime} \mathrm{N}\right)$ is located in the north of China and occupies a total area of $16,410 \mathrm{~km}^{2}$. The city lies on a plain surrounded by mountains on three sides. It comprises 16 districts. The main development pattern is a "single center-ring circuit" with the Forbidden City acting as the single center, ringed by five highways (Figure 1). The Haidian District $\left(39^{\circ} 53^{\prime}-40^{\circ} 09^{\prime} \mathrm{N}\right)$ is located in the northwest of Beijing. The average annual temperature is $12.5^{\circ} \mathrm{C}$, and the annual precipitation is $628.9 \mathrm{~mm}$ [32]. It has relatively abundant natural resources. There are 10 rivers (with a total length of $119.8 \mathrm{~km}$ ) running across the whole area, and the water area accounts for $41.28 \%$ of the entire water area of Beijing, ranking first among 16 districts. The Haidian District is surrounded by mountains and forests in the west. It is roughly separated into two parts by mountains: the impact built-up area in the south and the suburban area in the north.

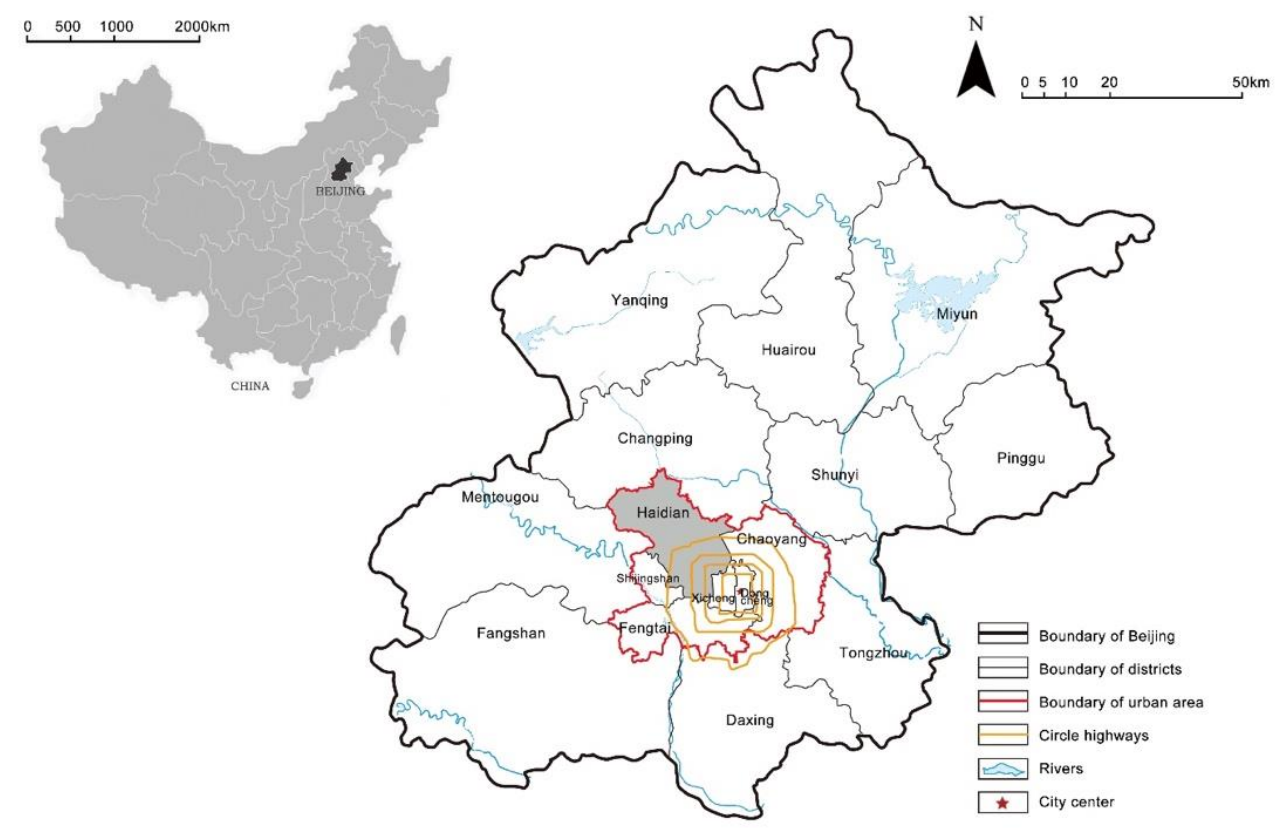

Figure 1. Location of the Haidian District.

In this study, landscape connectivity analysis is based on focal species. The focal species selection and dispersal distance of them are vital to the landscape connectivity assessment. Focal species can indicate endangered species and guide the management of them [33]. On the one side, in Beijing, large mammals are rare and mostly inhabit the mountain areas with high altitudes. Also, small mammals such as chipmunks are not sensitive to habitat changes resulting from urban expansion. In this context, a middle-size mammal called the raccoon dog (Nyctereutes procyonoides) was chosen as a focal species, and it is a first-grade protection animal of Beijing. On the other side, Beijing is located in the transition zone between subtropical and subarctic. Owing to migration channels, the bird richness of Beijing accounts for nearly one-third of that of China. Accordingly, we also selected the ring-necked pheasant (Phasianus colchicus) as a focal species. Dispersal distance, which is species specific, is a critical process determining the distance threshold. The maximal dispersal distance of the raccoon dog is $2 \mathrm{~km}$ according to [34]; Leif [35] radio-marked 95 male pheasants over five years (1997-2001) and obtained an average dispersal of $3.2 \pm 0.3 \mathrm{~km}$. We assigned the dispersal distance of the ring-necked pheasant as $3.2 \mathrm{~km}$ based on Leif's research. The selected focal species have common characteristics: (1) they rely on green space; (2) they are threatened by urban expansion; (3) their dispersal ability is ordinary. 


\subsection{Data}

We used the high-resolution remote sensing images (RS-images) to extract land cover information. From the Gaofen-2 (GF-2) satellite, which was successfully launched on 19 August 2014, we used a GF-2 image (resolution $=0.8 \mathrm{~m}$ ) of the Haidian District, which was captured on 12 September 2015 with a solar azimuth angle of $37^{\circ}$ and an axial inclination of $94^{\circ}$. There were four multispectral bands (red, green, blue, and near-infrared) with a resolution of $3.2 \mathrm{~m}$ and a panchromatic band with a resolution of $0.8 \mathrm{~m}$. They were fused into a four-band, pan-sharpened multispectral image.

\section{Method}

\subsection{Data Processing and Landscape Fragmentation Analysis}

Image processing was performed using ENVI (Harris Geospatial, Boulder, CO, USA) and eCognition (Trimble, Westminster, CA, USA), which can extract meaningful information from remote sensing image. Before classification, images had to be segmented. The scale parameter refers to the threshold of the heterogeneity variation allowed in the segmentation process [36]. Scale parameter will affect the accuracy and efficiency of the extraction process. Multiscale segmentation was used to fix this problem. It is the foundation procedure of object-based image analysis (OBIA) to convert discrete pixels of RS-images into a homogeneous image object $[37,38]$. Depending on the required land-cover categories (green space, agriculture land, built-up area, transportation area, and water), the segmentation scale parameter and the hierarchical relationship were identified according to their characteristics after several attempts to obtain a satisfactory result.

Difficulties in pixel-based classification caused by increasing satellite resolution led to the development of OBIA [39]. By identifying spectral and spatial information (the normalized difference vegetation index, geometry, brightness, texture, neighborhood attributes), adjacent pixels are grouped into multipixel objects $[40,41]$. We adopted the K-nearest neighbor method and obtained the land-cover categories by creating the following spectral characteristics: normalized difference vegetation index, standard deviation, maximum difference, brightness, length/width, roundness, and aspect ratio.

Landscape metrics, for example, the L-Z complexity method [42] and mean patch shape fragmentation index [43], have been developed to quantify landscape fragmentation. Landscape fragmentation processes can be classified into perforation, subdivision, shrinkage, and attribution, which can also be measured [44]. However, these studies evaluate the overall landscape fragmentation without locating where fragmentation is taking place. According to the definition of landscape fragmentation, fragmentation will bring two results: one is the decrease in patch area, and the other is the increase in patch number. In other words, the mean patch area will decrease. Therefore, we used the mean patch area to quantify the fragmentation. The RS-image was clipped into grids (size $=1 \mathrm{~km} \times 1 \mathrm{~km}$ ) using the Fishnet tool in ArcGIS. The area and number of patches in each grid were summarized, then the mean patch area was calculated to indicate its landscape fragmentation.

\subsection{Habitat Identification}

Morphological spatial pattern analysis (MSPA) and the delta of the probability of connectivity (dPC) metric were combined into a two-step methodology to identify habitats. First, we reclassified the landscape into seven categories based on morphological characteristics in GuidosToolbox (http:/ / forest.jrc.ec.europa.eu/download/software/guidos/): core, edge, perforation, bridge, loop, branch, and islet [45]. We extracted the core area for step 2, which is regarded as the most important area for landscape connectivity. Unlike traditional methods that focus on the area or importance of a single patch without taking the integrated landscape connectivity into account, this method provides the four- or eight-neighbor rule since the connectivity analysis is conducted on a raster grid. It allows automatic classification based on geometric concepts at a pixel level.

According to the habitat type of the raccoon dog and the ring-necked pheasant, in this case, we overlaid the woodland and waterbody as a potential habitat for the former, meanwhile the 
woodland and agriculture land were overlaid as the latter's potential habitat for the following analysis. After reclassifying the land cover into the foreground (potential habitat) and background (all other land cover types), we obtained a potential habitat and nonpotential habitat binary map. Due to the upper limit of GuidosToolbox being 10,000 $\times 10,000$ pixels, the pixel size of $4 \mathrm{~m} \times 4 \mathrm{~m}$ was the upper limitation. We set the edge width as 5 pixels and extracted the "core" area under the eight-neighbor rule to identify ecological habitats in the following analyses.

The probability of connectivity (PC) can not only quantitatively describe the landscape connectivity, but it can also identify patches with important connectivity. PC is calculated by the following formula $(0<\mathrm{PC}<1)$ :

$$
\mathrm{PC}=\frac{\sum_{i=1}^{n} \sum_{j=1, i \neq j}^{n} P_{i j}^{*} a_{i} a_{j}}{A_{L}^{2}}
$$

where $a_{i}$ and $a_{j}$ refer to areas of habitats $i$ and $j$; the connection strength between any pair of patches is marked by $p_{i j}$, which describes the ease of dispersal between patch $i$ and $j$; and $A_{L}$ is the area of the Haidian District, including all kinds of land cover.

The delta of PC (dPC) can calculate the contribution of each patch to the overall connectivity of the ecological network. It can identify patches that are crucial to PC. dPC is calculated according to the following formula:

$$
\mathrm{dPC}(\%)=\frac{P C-P C^{\prime}}{P C} \times 100 \%
$$

where $P C$ is the overall landscape connectivity and $P C^{\prime}$ is the overall landscape connectivity after removing a patch from the original landscape. The change of the overall landscape connectivity is regarded as the importance value of the removed patch.

Further details of PC and dPC can be found in previous studies [46-48]. We adopted Conefor Sensinode 2.6 software (http:/ / www.conefor.org/) to calculate the dPC values. As the dispersal ability of different species varies, we assigned the dispersal distance as $2.0 \mathrm{~km}$ and $3.2 \mathrm{~km}$ for raccoon dog and ring-necked pheasant, respectively. We set 0.5 as the probability of dispersal between patches if the distance between two patches was within the threshold [46]. Finally, the top 15 patches with the highest dPC values were chosen as habitats.

\subsection{Least-Cost Path}

The least-cost path is often used to optimize a grid module. The resistance value of a grid describes its facilitating or impeding influences on dispersal processes of species. The resistance value is attached to each land cover unit to calculate the connectivity between two habitats [49]. The least-cost path model makes it possible to calculate the minimum cumulative link (corridors) between the target patch and the nearest source patch (habitat). We calculated the path of least resistance for the organism to migrate along and obtained the potential corridors between source patches using the "cost path" analysis in ArcGIS. The different resistance values of each land cover class were the key factors affecting the result. Table 1 indicates the assigned resistance values with reference to [50].

Table 1. Landscape resistance value.

\begin{tabular}{cccc}
\hline \multirow{2}{*}{ Land Cover Class } & \multicolumn{2}{c}{ Resistance Value } \\
\cline { 3 - 4 } & & $\begin{array}{c}\text { Ring-Necked Pheasant } \\
\text { (Phasianus colchicus) }\end{array}$ & $\begin{array}{c}\text { Raccoon Dog } \\
\text { (Nyctereutes procyonoides) }\end{array}$ \\
\hline Core & Habitat & 1 & 1 \\
& Important core & 5 & 5 \\
Woodland & Ordinary core & 10 & 10 \\
Agriculture land & 20 & 20 \\
Waterbody & 20 & 50 \\
Road & 100 & 20 \\
Built-up area & 500 & 500 \\
\hline
\end{tabular}




\section{Results}

\subsection{Land Cover and Landscape Fragmentation}

We obtained a land-cover map using OBIA, shown in Figure 2a. In the suburban area, the land cover map was a huge mosaic mixed with woodland, agriculture land, and built-up areas. Here, disordered urbanization has resulted in severe landscape fragmentation. In contrast, the urban area is highly constructed; green space was mainly composed of parks and roadside green space. In both suburban and urban areas, roads and highways fragmented the green space. Table 2 shows the land cover classification results: woodland occupies $34.1 \%$ of the total area and the proportion of the built-up area is $41 \%$. We divided the land-use categories result using the Fishnet tool in GIS and identified the center point of each grid $(n=429)$ as a sample of visual interpretation. We tested the classification accuracy through a confusion matrix. The overall accuracy was $85.5 \%$, and the kappa coefficient was 79.23 .

Table 2. Area and proportion of different land-cover categories.

\begin{tabular}{ccc}
\hline Class & Area (ha) & Proportion of Total \\
\hline Built-up area & 19,543 & $41.0 \%$ \\
Road & 2257 & $4.7 \%$ \\
Woodland & 16,258 & $34.1 \%$ \\
Agriculture land & 8747 & $18.4 \%$ \\
Waterbody & 858 & $1.8 \%$ \\
Total & 47,663 & $100 \%$ \\
\hline
\end{tabular}

We roughly simulated the landscape fragmentation using the mean patch area, and landscape only included woodland as a typical example. Figure $2 b$ shows that fragmentation is relatively severe in both urban and suburban areas. The legend on the left side of Figure $2 \mathrm{~b}$ shows the different levels of fragmentation and the accounts for the overall proportion of each level. The value of $50-100$ is $11 \%$ of the whole; on the contrary, the value of $0-6$ is $65 \%$ of the whole, which means $65 \%$ of the study area has a serious landscape fragmentation.

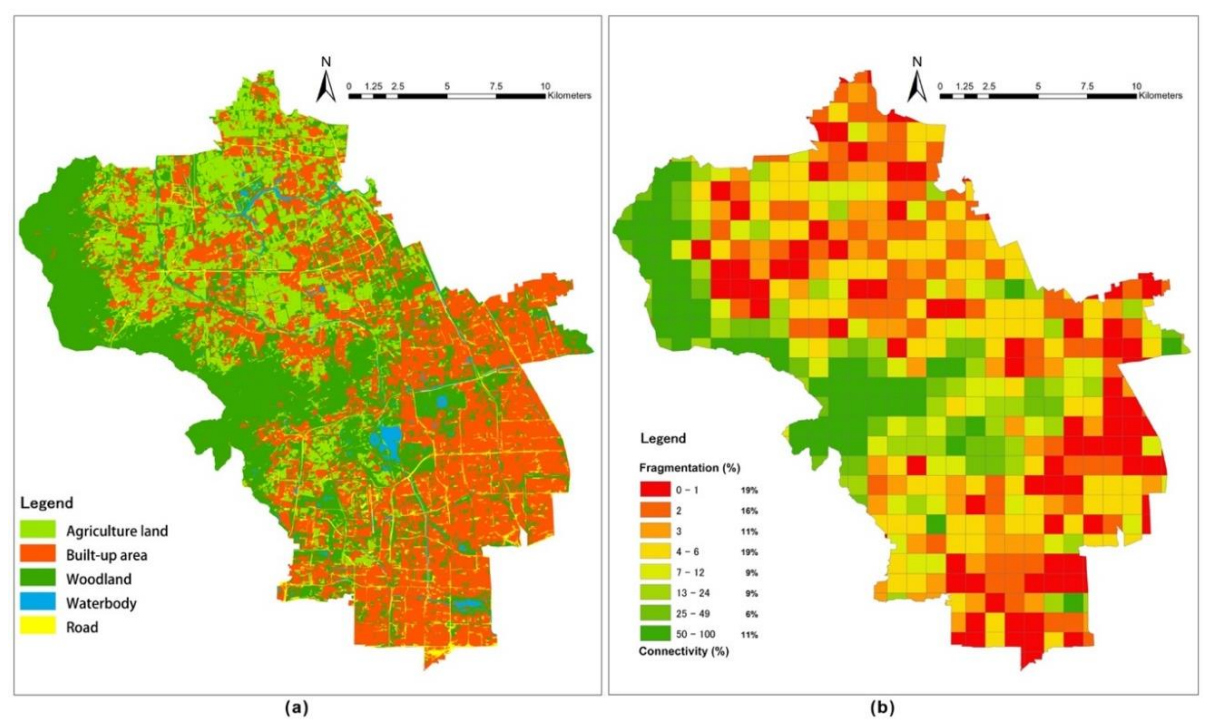

Figure 2. (a) Land cover classification of Haidian in 2015; (b) landscape fragmentation analysis of Haidian in 2015, which shows that fragmentation is relatively serious in both urban and suburban areas. 


\subsection{The Results of Habitats and Corridors}

We obtained the MSPA-based landscape classification map (Figure 3). The amount of core patches is favorable but they are relatively unevenly distributed. For the ring-necked pheasant in Figure 3a, core patches are distributed in the mountain area and suburban area. For the raccoon dog in Figure $3 \mathrm{~b}$, core patches that contribute to the overall connectivity are mostly concentrated in the mountainous region and several green spaces around it.

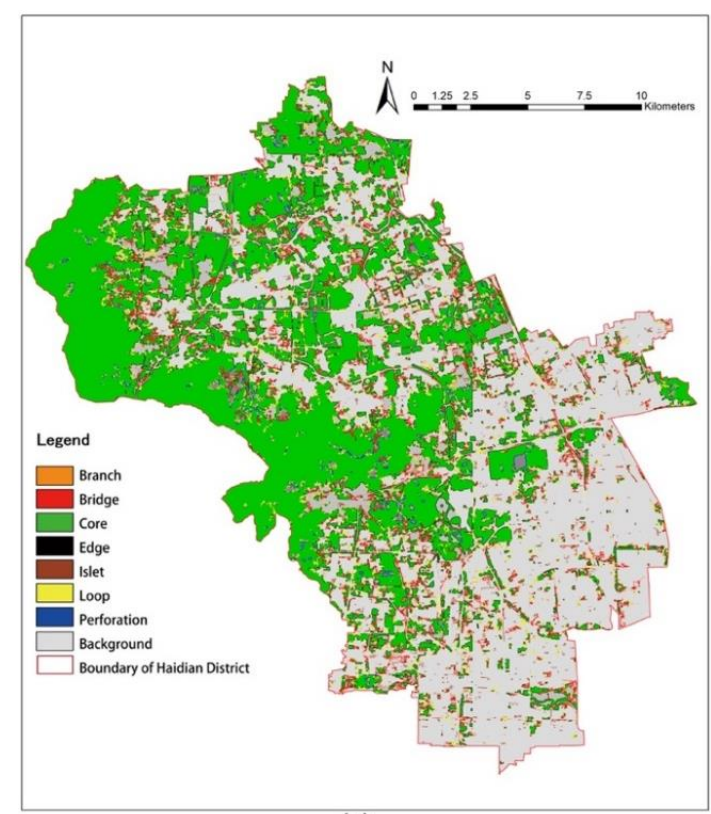

(a)

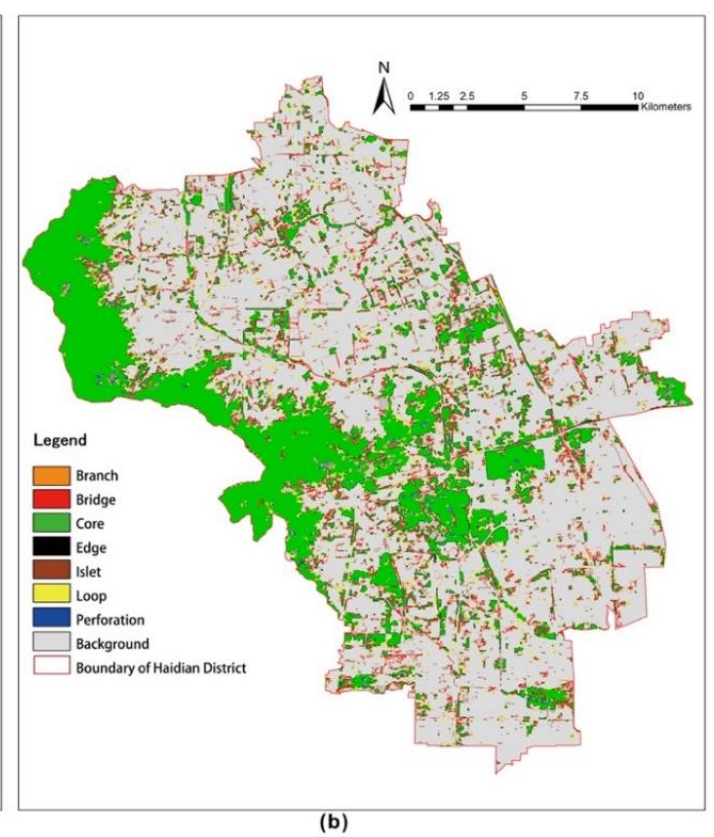

(b)

Figure 3. This figure shows the MSPA (morphological spatial pattern analysis) classification of Haidian according to different habitat types of focal species. (a) is based on the ring-necked pheasant; (b) is according to the raccoon dog.

The dPC value of each core patch with different dispersal distances considered ( $\mathrm{d}=2 \mathrm{~km}, 3.2 \mathrm{~km}$ ) was calculated (Table 3). Then, we obtained the importance rank map of the top 15 cores, as shown in Figure 4. The size of the green space is often regarded as the most essential characteristic in green space planning. However, the size of a patch is not proportional to its role in maintaining PC. In Figure 4a, although relatively small, Patch 3 and Patch 4 are more important than Patch 13 for landscape connectivity; also, in Figure 4b, compared with Patch 9 and Patch 14, Patch 4 and Patch 5 are much smaller in size, but have a higher dPC value. Besides, the geometry location of a patch is also unrelated to its $\mathrm{APC}$ value; a patch near the geometric center is not necessarily important to the PC value.

The mountain region, in terms of its high importance value and large area, has an utterly dominant advantage over other green spaces. When species need to migrate from a patch far away from the mountain area, they have to overcome more resistance. Adding or subtracting a habitat will lead to the change of the patch importance. In this case, the importance of patches far away from the mountain area is less than patches near the mountain area. In Figure 4a, since agriculture land is also included in the habitats, landscape connectivity seems to be favorable in the northern part of Haidan, i.e., the suburban areas. Compared with Patch 2 in Figure $4 \mathrm{~b}$, a part of the mountain areas, it is not that important in Figure $4 \mathrm{a}$ because patches are well-enough connected so that the relative importance of Patch 2 decreases. 
Table 3. Top 15 important core patches: Patch rank/No., dPC value, area.

\begin{tabular}{ccccc}
\hline & \multicolumn{2}{c}{$\begin{array}{c}\text { Ring-Necked Pheasant } \\
\text { Phasianus colchicus }\end{array}$} & \multicolumn{2}{c}{ Raccoon Dog } \\
Patch Rank/No. ${ }^{2}{ }^{2}$ & \multicolumn{2}{c}{ Nytes procyonoides } \\
\cline { 2 - 5 } & dPC $^{\mathbf{1}}$ & Area (ha) & dPC & Area (ha) \\
\hline 1 & 30.59 & 4153.8 & 22.11 & 2350.0 \\
2 & 12.26 & 518.9 & 9.56 & 503.8 \\
3 & 7.51 & 144.7 & 9.54 & 480.8 \\
4 & 6.76 & 62.9 & 3.88 & 57.2 \\
5 & 4.76 & 47.7 & 2.42 & 7.8 \\
6 & 4.71 & 143.7 & 2.14 & 5.2 \\
7 & 4.24 & 9.2 & 2.08 & 19.0 \\
8 & 3.25 & 96.2 & 1.94 & 18.0 \\
9 & 3.13 & 454.0 & 1.93 & 2188.0 \\
10 & 3.10 & 260.0 & 1.87 & 6.0 \\
11 & 2.84 & 207.5 & 1.73 & 17.3 \\
12 & 2.62 & 3.6 & 1.73 & 43.1 \\
13 & 2.34 & 86.1 & 1.72 & 11.3 \\
14 & 2.20 & 1.8 & 1.65 & 285.7 \\
15 & 2.00 & 8.0 & 1.51 & 1.1 \\
\hline
\end{tabular}

${ }^{1}$ Note: dPC is an indicator of importance value for a single on maintaining the overall landscape connectivity. ${ }^{2}$ Note: The importance value is species specific. We assign the No. of a patch according with its dPC value, i.e., Patch 1 is the most important patch.

Figure 5 shows the result of overlaying Figure 4a,b. The green space refers to all core areas, including woodland, agriculture land, and waterbody. We did not assign a specific width to the corridors; instead, they can only represent the possible dispersal path of the focal species. According to the resistance value, these corridors are mainly woodland or agriculture land, mixed with other land covers. The calculation of corridors is based on the current land cover and landscape patterns. Our analysis revealed that: (a) there is a lack of woodland for forest species in the central urban area and suburban area; (b) green spaces in the suburban and urban areas are poorly connected; and (c) habitats are distributed in the mountain area and its surroundings. Due to the high resistance value of built-up areas, maintaining species migration is supposed to be more difficult in suburban and urban areas.

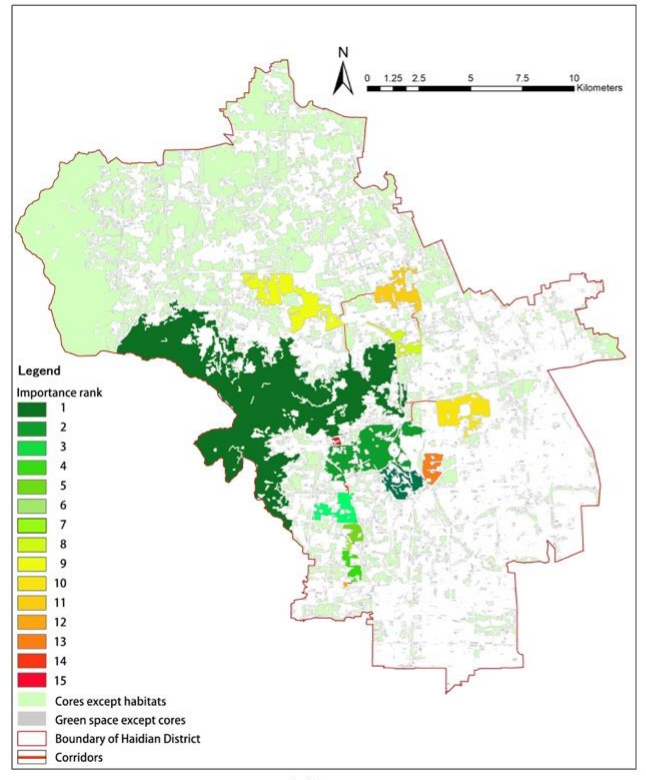

(a)

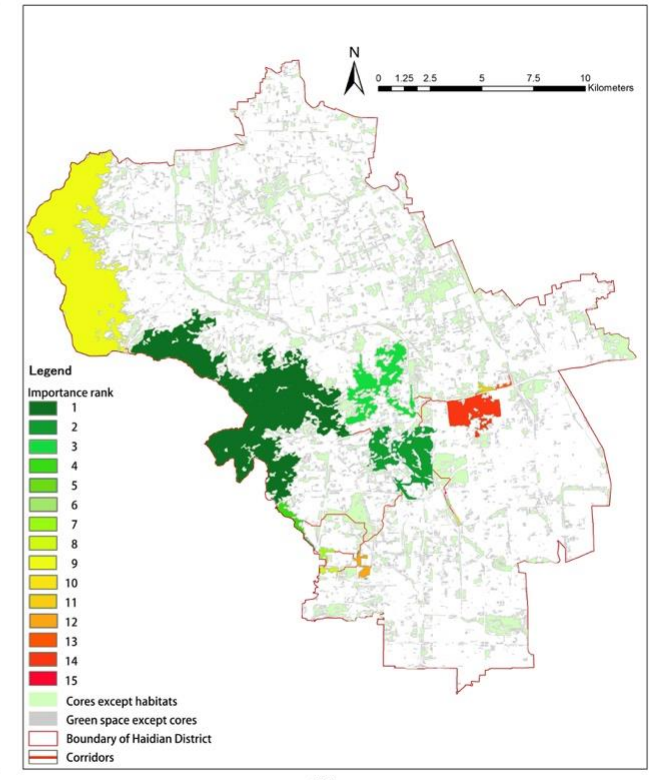

(b)

Figure 4. Importance rank of habitats and potential corridors. (a) is according to the ring-necked pheasant (Phasianus colchicus); (b) is according to the raccoon dog (Nyctereutes procyonoides). 


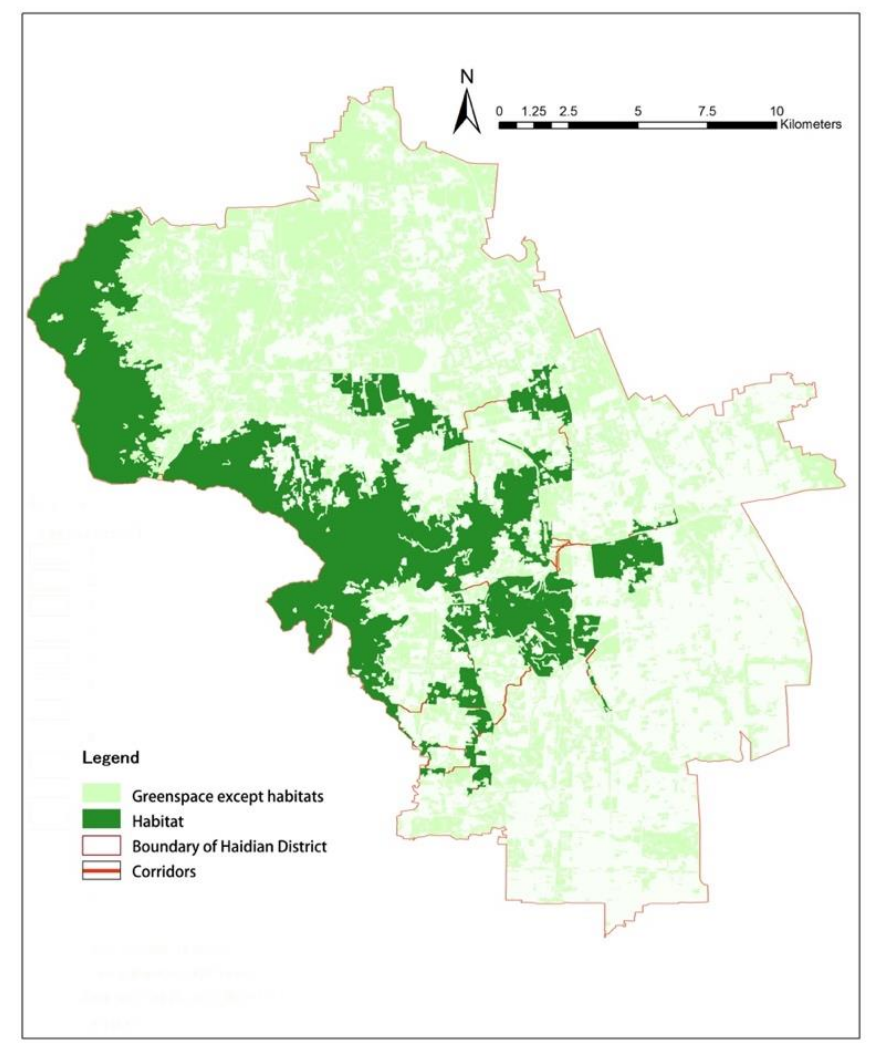

Figure 5. Ecological network of Haidian, obtained by overlaying habitats and corridors for the ring-necked pheasant and the raccoon dog.

\section{Discussion}

\subsection{The Correlation between Landscape Connectivity and Biodiversity}

It is believed that the viability of a species depends on its ability to cross unsuitable habitats and on dispersal from one patch to another [4], which is also the starting point of landscape ecology. However, it is still a tricky problem to test the correlation between landscape connectivity and biodiversity in this study, considering that a species survey usually takes a couple of years to get a considerable number of samples. According to a review [51], among the 94 studies about species and ecological networks (1990-2013), only 34 of them discussed landscape connectivity and biodiversity (richness, occurrence, abundance, etc.). Of these 34 studies, $32.4 \%$ show no significant correlation and $67.4 \%$ of them refer to significant species responding to landscape connectivity. These studies offer essential empirical evidence in supporting the correlation between landscape connectivity and biodiversity.

\subsection{Contributions to the Literature}

Ecological network planning in urbanized areas should not only consider the connection between habitats but also the characteristics of the species. The existing studies on landscape connectivity of Beijing or other cities in China prefer to make an overall evaluation of landscape patterns using landscape metrics, i.e., FRAGSTATS [52,53]. Further, several studies use landscape connectivity to guide wildlife protection area planning [54,55]. Compared to other research that focuses explicitly on certain species $[29,30,56]$, we proposed a paradigm shown in Figure 6 to evaluate and optimize the landscape pattern using a species-specific method. In this case, habitats and corridors are identified under the consideration of the habitat type and dispersal distance of focal species. Analogously, we can also identify a potential ecological network for any species or community. 
We believe that landscape connectivity promotion, taking landscape patterns as the starting point, can be easily applied and promoted in studies or projects such as urban planning and biodiversity conservation at different spatiotemporal scales. The current green space planning in China does not make specific and reasonable ecological network planning according to different species. Urban planners can regard our green space importance evaluation as a reference. They can easily figure out the importance of a patch for different species. Especially when there is a demand that a certain amount of green space should be turned into a built-up area due to urbanization, our study can help urban planners make a wise choice to balance urban construction and biodiversity conservation. A biologist can apply our method to species-specific research, especially for endangered species, in conjunction with species surveys to collect information such as breeding and feeding habits, dispersal ability, habitat requirement, home range size, and so on.

\subsection{Limitations of Results}

Intensive studies have been conducted by scholars towards the identification of a preferable approach to quantifying and incorporating connectivity into green space planning [57-60]. Pascual-Hortal and Saura [59] proposed that dPC performs best among other metrics they have put forward for identifying the importance value of a patch. We adopted the MSPA and APC to identify key green space as habitats.
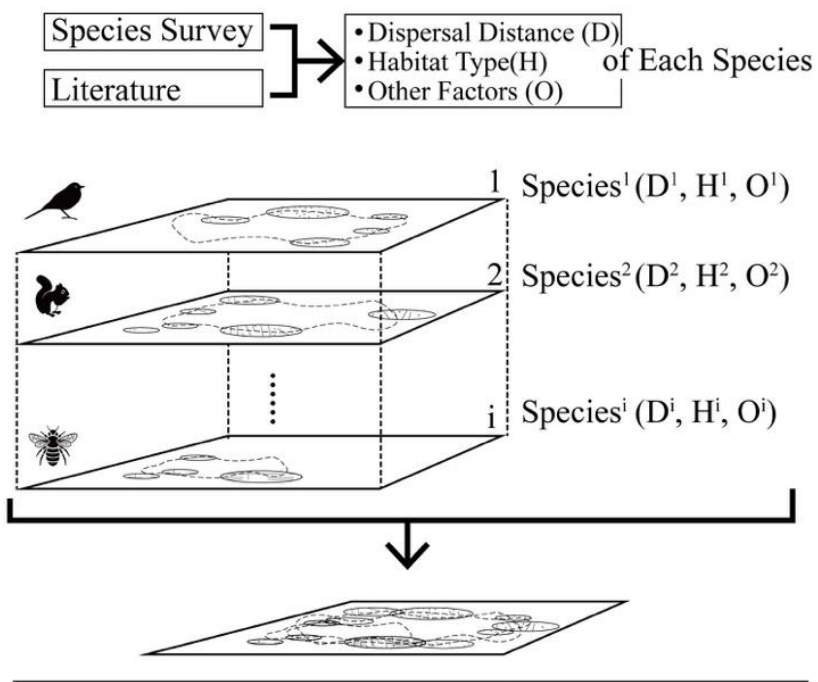

A Paradigm of Ecological Network Identification for Multi-Species

Figure 6. A paradigm of ecological network identification of multiple species. Dispersal distance, habitat type, and other factors (altitude, slope, home range size, vegetation configuration, adaptation to urban or not, residence type, etc.) can be obtained from species surveys and literature reviews. The simulated scenario of each species will be overlaid to get a final ecological network.

However, we acknowledge the limitation of this study regarding resistance value and the dispersal distance. For resistance value, we extracted the woodland area with no distinction between original forest and plantations; further, it did not include environmental information of vegetation condition, soil condition, slope, and altitude. Although we identified the resistance value according to other Chinese scholars' research [50], it was subjective to some extent. It is the same for dispersal distance, which is usually discussed from two aspects: (1) dispersal distance scenario is conducted to figure out its effect on landscape connectivity [29,61-63]; (2) dispersal distance is identified according to specific species $[64,65]$. Although we assigned the dispersal distance for focal species according to published research papers, the dispersal distance of most species remains to be studied. Further, different land types may be used by a given species for different purposes or to different degrees [66]. Thus, 
the specific needs and behaviors of certain species should be considered in future work. Land cover configuration, distance to water resources, distance to the residential area, and vegetation configuration may be factors affecting habitat selection.

\section{Conclusions and Further Possibilities}

In this study, we analyzed potential network configurations by combining the method of OBIA, MSPA, PC, and the least-cost path. Landscape metrics and models have proven their efficiency in wildlife conservation planning and green space management $[65,66]$. We went deeper into the details of landscape models in habitat identification and distance thresholds. Two focal species were adopted in order to get a species-specific result. The habitat type and dispersal distance of each species were obtained from the existing research. Results obtained from the landscape analysis show that: (1) there is a lack of woodland for forest species both in the urban and suburb areas, where landscape fragmentation resulting from urban expansion is taking place; (2) the importance of a patch is determined by its role in maintaining the overall landscape connectivity; and (3) this paper fully shows the different needs of habitats and corridors for different species.

In summary, a multispecies paradigm is put forward to solve the deficiencies in the existing research, which can be adopted for conservation planning and green space management. Taking endangered birds conservation as an example, first of all, factors affecting the diversity of endangered birds should be investigated through bird surveys and literature reviews. After figuring out species' home range, dispersal distance, demand for habitats, etc., the final result can be obtained by overlaying all scenarios for all species.

Author Contributions: Conceptualization, K.S.; Data curation, S.G. and C.S.; Formal analysis, C.S.; Funding acquisition, W.Y.; Project administration, W.Y.; Supervision, W.Y.; Validation, K.S.; Writing-original draft, S.G.; Writing-review \& editing, S.G.

Funding: This work was supported by [The National Natural Science Foundation of China 494 No. 31500580], [The China postdoctoral foundation No. 2016M591091] and [Science and Technology Innovation Project of Beijing Forestry University No. 2017ZY19].

Acknowledgments: The remote sensing data and data processing for this research were supported by Urban Spatial Information Engineering Laboratory of Beijing Forestry University.

Conflicts of Interest: The authors declare no conflict of interest.

\section{References}

1. Kabisch, N.; Haase, D. Green spaces of European cities revisited for 1990-2006. Landsc. Urban Plan. 2013, 110, 113-122. [CrossRef]

2. Xu, L.; You, H.; Li, D.; Yu, K. Urban green spaces, their spatial pattern, and ecosystem service value: The case of Beijing. Habitat Int. 2016, 56, 84-95. [CrossRef]

3. Miller, W.; Collins, M.G.; Steiner, F.R.; Cook, E. An approach for greenway suitability analysis. Landsc. Urban Plan. 1998, 42, 91-105. [CrossRef]

4. Tannier, C.; Foltête, J.C.; Girardet, X. Assessing the capacity of different urban forms to preserve the connectivity of ecological habitats. Landsc. Urban Plan. 2012, 105, 128-139. [CrossRef]

5. Harris, L.D. The Fragmented Forest: Island Biogeography Theory and the Preservation of Biotic Diversity; University of Chicago Press: Chicago, IL, USA, 1984; ISBN 9780226317649.

6. Cook, E.A. Landscape structure indices for assessing urban ecological networks. Landsc. Urban Plan. 2002, 58, 269-280. [CrossRef]

7. Langevelde, F.V. Modelling the negative effects of landscape fragmentation on habitat selection. Ecol. Inform. 2015, 30, 271-276. [CrossRef]

8. Taylor, P.D.; Fahrig, L.; Henein, K.; Merriam, G. Connectivity is a vital element of landscape structure. Oikos 1993, 68, 571-573. [CrossRef]

9. Forman, R.T.; Collinge, S.K. Nature conserved in changing landscapes with and without spatial planning. Landsc. Urban Plan. 1997, 37, 129-135. [CrossRef] 
10. Turner, M.G. Landscape ecology: The effect of pattern on process. Annu. Rev. Ecol. Syst. 1989, 20, 171-197. [CrossRef]

11. Forman, R.T. Land Mosaics: The Ecology of Landscapes and Regions 1995; Island Press: Washington, DC, USA, 2014; p. 217, ISBN 978-1-61091-491-8.

12. Pătru-Stupariu, I.; Stupariu, M.S.; Stoicescu, I.; Peringer, A.; Buttler, A.; Fürst, C. Integrating geo-biodiversity features in the analysis of landscape patterns. Ecol. Indic. 2017, 80, 363-375. [CrossRef]

13. Wilson, S.; Mitchell, G.W.; Pasher, J.; McGovern, M.; Hudson, M.A.R.; Fahrig, L. Influence of crop type, heterogeneity and woody structure on avian biodiversity in agricultural landscapes. Ecol. Indic. 2017, 83, 218-226. [CrossRef]

14. Buyantuyev, A.; Wu, J. Urban heat islands and landscape heterogeneity: Linking spatiotemporal variations in surface temperatures to land-cover and socioeconomic patterns. Landsc. Ecol. 2010, 25, 17-33. [CrossRef]

15. Connors, J.P.; Galletti, C.S.; Chow, W.T. Landscape configuration and urban heat island effects: Assessing the relationship between landscape characteristics and land surface temperature in Phoenix, Arizona. Landsc. Ecol. 2013, 28, 271-283. [CrossRef]

16. Guo, G.; Wu, Z.; Xiao, R.; Chen, Y.; Liu, X.; Zhang, X. Impacts of urban biophysical composition on land surface temperature in urban heat island clusters. Landsc. Urban Plan. 2015, 135, 1-10. [CrossRef]

17. Grimm, N.B.; Faeth, S.H.; Golubiewski, N.E.; Redman, C.L.; Wu, J.; Bai, X.; Briggs, J.M. Global change and the ecology of cities. Science 2008, 319, 756-760. [CrossRef] [PubMed]

18. Crooks, K.R.; Sanjayan, M. (Eds.) Connectivity Conservation; Cambridge University Press: Cambridge, UK, 2006; Volume 14, ISBN 9780511754821.

19. Taylor, P.D. Landscape connectivity: A return to the basics. Connect. Conserv. 2006, 29-43. [CrossRef]

20. Lookingbill, T.R.; Elmore, A.J.; Engelhardt, K.A.; Churchill, J.B.; Gates, J.E.; Johnson, J.B. Influence of wetland networks on bat activity in mixed-use landscapes. Biol. Conserv. 2010, 143, 974-983. [CrossRef]

21. Grunwald, S. (Ed.) Environmental Soil-Landscape Modeling: Geographic Information Technologies and Pedometrics; CRC Press: Boca Raton, FL, USA, 2016; ISBN 9781420028188.

22. Urban, D.; Keitt, T. Landscape connectivity: A graph-theoretic perspective. Ecology 2001, 82, 1205-1218. [CrossRef]

23. Adriaensen, F.; Chardon, J.P.; De Blust, G.; Swinnen, E.; Villalba, S.; Gulinck, H.; Matthysen, E. The application of 'least-cost' modelling as a functional landscape model. Landsc. Urban Plan. 2003, 64, 233-247. [CrossRef]

24. Feranec, J.; Jaffrain, G.; Soukup, T.; Hazeu, G. Determining changes and flows in European landscapes 1990-2000 using CORINE land cover data. Appl. Geogr. 2010, 30, 19-35. [CrossRef]

25. Wickham, J.D.; Riitters, K.H.; Wade, T.G.; Vogt, P. A national assessment of green infrastructure and change for the conterminous United States using morphological image processing. Landsc. Urban Plan. 2010, 94, 186-195. [CrossRef]

26. Saura, S.; Vogt, P.; Velázquez, J.; Hernando, A.; Tejera, R. Key structural forest connectors can be identified by combining landscape spatial pattern and network analyses. For. Ecol. Manag. 2011, 262, 150-160. [CrossRef]

27. Cushman, S.A.; Landguth, E.L.; Flather, C.H. Evaluating population connectivity for species of conservation concern in the American Great Plains. Biodivers. Conserv. 2013, 22, 2583-2605. [CrossRef]

28. Baguette, M.; Blanchet, S.; Legrand, D.; Stevens, V.M.; Turlure, C. Individual dispersal, landscape connectivity and ecological networks. Biol. Rev. 2013, 88, 310-326. [CrossRef] [PubMed]

29. Gurrutxaga, M.; Rubio, L.; Saura, S. Key connectors in protected forest area networks and the impact of highways: A transnational case study from the Cantabrian Range to the Western Alps (SW Europe). Landsc. Urban Plan. 2011, 101, 310-320. [CrossRef]

30. Maiorano, L.; Boitani, L.; Chiaverini, L.; Ciucci, P. Uncertainties in the identification of potential dispersal corridors: The importance of behaviour, sex, and algorithm. Basic Appl. Ecol. 2017, 21, 66-75. [CrossRef]

31. Minor, E.S.; Lookingbill, T.R. A Multiscale Network Analysis of Protected-Area Connectivity for Mammals in the United States. Conserv. Biol. 2010, 24, 1549-1558. [CrossRef] [PubMed]

32. Beijing Municipal Statistical Bureau. Beijing Statistical Yearbook; China Statistics Press: Beijing, China, 2015. Available online: http:/ / www.bjstats.gov.cn/nj/main/2015-tjnj/indexee.htm (accessed on 25 April 2018).

33. Marcot, B.G.; Flather, C.H. Species-level strategies for conserving rare or little-known species [Chapter 6]. In Conservation of Rare or Little-Known Species: Biological, Social, and Economic Considerations; Raphael, M.G., Molina, R., Eds.; Island Press: Washington, DC, USA, 2007; pp. 125-164, ISBN 9781597267496. 
34. Tokue, Y.; Osawa, S.; Imamura, F. A study about migration and dispersal distance of animals for ecological network planning in urban area. J. Jpn. Soc. Reveg. Technol. 2012, 37, 203-206. (In Japanese) [CrossRef]

35. Leif, A.P. Spatial ecology and habitat selection of breeding male pheasants. Wildl. Soc. Bull. 2005, 33, 130-141. [CrossRef]

36. Ming, D.; Li, J.; Wang, J.; Zhang, M. Scale parameter selection by spatial statistics for GeOBIA: Using mean-shift based multi-scale segmentation as an example. ISPRS J. Photogramm. Remote Sens. 2015, 106, 28-41. [CrossRef]

37. Kettig, R.L.; Landgrebe, D.A. Classification of multispectral image data by extraction and classification of homogeneous objects. IEEE Trans. Geosci. Electron. 1976, 14, 19-26. [CrossRef]

38. Vieira, M.A.; Formaggio, A.R.; Rennó, C.D.; Atzberger, C.; Aguiar, D.A.; Mello, M.P. Object based image analysis and data mining applied to a remotely sensed Landsat time-series to map sugarcane over large areas. Remote Sens. Environ. 2012, 123, 553-562. [CrossRef]

39. Blaschke, T. Object based image analysis for remote sensing. ISPRS J. Photogramm. Remote Sens. 2010, 65, 2-16. [CrossRef]

40. Aplin, P.; Atkinson, P.M.; Curran, P.J. Per-field classification of land use using the forthcoming very fine spatial resolution satellite sensors: Problems and potential solutions. Adv. Remote Sens. GIS Anal. 1999, 219-239. [CrossRef]

41. Congalton, R.; Green, K. Assessing the Accuracy of Remotely Sensed Data; CRC Press: Boca Raton, FL, USA, 2008; ISBN 9781420055139.

42. Li, S.; Chang, Q.; Peng, J.; Wang, Y. Indicating landscape fragmentation using l-z complexity. Ecol. Indic. 2009, 9, 780-790. [CrossRef]

43. Jiang, P.; Cheng, L.; Li, M.; Zhao, R.; Huang, Q. Analysis of landscape fragmentation processes and driving forces in wetlands in arid areas: A case study of the middle reaches of the Heihe river, China. Ecol. Indic. 2014, 46, 240-252. [CrossRef]

44. Li, S.; Yang, B. Introducing a new method for assessing spatially explicit processes of landscape fragmentation. Ecol. Indic. 2015, 56, 116-124. [CrossRef]

45. Soille, P.; Vogt, P. Morphological segmentation of binary patterns. Pattern Recognit. Lett. 2009, 30, 456-459. [CrossRef]

46. Saura, S.; Pascual-Hortal, L. A new habitat availability index to integrate connectivity in landscape conservation planning: Comparison with existing indices and application to a case study. Landsc. Urban Plan. 2007, 83, 91-103. [CrossRef]

47. Saura, S.; Torne, J. Conefor Sensinode 2.2: A software package for quantifying the importance of habitat patches for landscape connectivity. Environ. Model. Softw. 2009, 24, 135-139. [CrossRef]

48. Saura, S.; Estreguil, C.; Mouton, C.; Rodríguez-Freire, M. Network analysis to assess landscape connectivity trends: Application to European forests (1990-2000). Ecol. Indic. 2011, 11, 407-416. [CrossRef]

49. Bunn, A.G.; Urban, D.L.; Keitt, T.H. Landscape connectivity: A conservation application of graph theory. J. Environ. Manag. 2000, 59, 265-278. [CrossRef]

50. Kong, F.; Yin, H.; Nakagoshi, N.; Zong, Y. Urban green space network development for biodiversity conservation: Identification based on graph theory and gravity modeling. Landsc. Urban Plan. 2010, 95, 16-27. [CrossRef]

51. Humphrey, J.W.; Watts, K.; Fuentes-Montemayor, E.; Macgregor, N.A.; Peace, A.J.; Park, K.J. What can studies of woodland fragmentation and creation tell us about ecological networks? A literature review and synthesis. Landsc. Ecol. 2015, 30, 21-50. [CrossRef]

52. Zhang, L.; Wu, J.; Zhen, Y.; Shu, J. Retracted: A GIS-based gradient analysis of urban landscape pattern of Shanghai metropolitan area, China. Landsc. Urban Plan. 2004, 69, 1-16. [CrossRef]

53. Zhang, L.; Wang, H. Planning an ecological network of Xiamen island (China) using landscape metrics and network analysis. Landsc. Urban Plan. 2006, 78, 449-456. [CrossRef]

54. Zhao, H.; Liu, S.; Dong, S.; Su, X.; Liu, Q.; Deng, L. Characterizing the importance of habitat patches in maintaining landscape connectivity for Tibetan antelope in the Altun Mountain National Nature Reserve, China. Ecol. Res. 2014, 29, 1065-1075. [CrossRef]

55. Liu, F.; Mcshea, W.J.; Li, D. Correlating habitat suitability with landscape connectivity: A case study of Sichuan golden monkey in China. Ecol. Model. 2016, 353, 37-46. [CrossRef] 
56. Matsuba, M.; Nishijima, S.; Katoh, K. Effectiveness of corridor vegetation depends on urbanization tolerance of forest birds in central Tokyo, Japan. Urban For. Urban Green. 2016, 18, 173-181. [CrossRef]

57. McGarigal, K.; Cushman, S.A.; Neel, M.C.; Ene, E. FRAGSTATS: Spatial Pattern Analysis Program for Categorical Maps; University of Massachusetts: Amherst, MA, USA, 2002.

58. Marulli, J.; Mallarach, J.M. A GIS methodology for assessing ecological connectivity: Application to the Barcelona Metropolitan Area. Landsc. Urban Plan. 2005, 71, 243-262. [CrossRef]

59. Pascual-Hortal, L.; Saura, S. Impact of spatial scale on the identification of critical habitat patches for the maintenance of landscape connectivity. Landsc. Urban Plan. 2007, 83, 176-186. [CrossRef]

60. Pascual-Hortal, L.; Saura, S. Integrating landscape connectivity in broad-scale forest planning through a new graph-based habitat availability methodology: Application to capercaillie (Tetrao urogallus) in Catalonia (NE Spain). Eur. J. For. Res. 2008, 127, 23-31. [CrossRef]

61. Freeman, R.E.; Ray, R.O. Landscape ecology practice by small scale river conservation groups. Landsc. Urban Plan. 2001, 56, 171-184. [CrossRef]

62. Freeman, R.C.; Bell, K.P. Conservation versus cluster subdivisions and implications for habitat connectivity. Landsc. Urban Plan. 2011, 101, 30-42. [CrossRef]

63. Devi, B.S.; Murthy, M.S.R.; Debnath, B.; Jha, C.S. Forest patch connectivity diagnostics and prioritization using graph theory. Ecol. Model. 2013, 251, 279-287. [CrossRef]

64. Closset-Kopp, D.; Wasof, S.; Decocq, G. Using process-based indicator species to evaluate ecological corridors in fragmented landscapes. Biol. Conserv. 2016, 201, 152-159. [CrossRef]

65. Moqanaki, E.M.; Cushman, S.A. All roads lead to Iran: Predicting landscape connectivity of the last stronghold for the critically endangered Asiatic cheetah. Anim. Conserv. 2017, 20, 29-41. [CrossRef]

66. Mörtberg, U.M. Resident bird species in urban forest remnants; landscape and habitat perspectives. Landsc. Ecol. 2001, 16, 193-203. [CrossRef]

(C) 2018 by the authors. Licensee MDPI, Basel, Switzerland. This article is an open access article distributed under the terms and conditions of the Creative Commons Attribution (CC BY) license (http:/ / creativecommons.org/licenses/by/4.0/). 